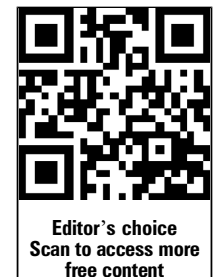

- Additional material is published online only. To view please visit the journal online (http://dx.doi.org/10.1136/ postgradmedj-2012-131474).

${ }^{1}$ Great Western Hospital, Swindon, UK

${ }^{2}$ Child Health Department, BANES PCT, Bath, UK

\section{Correspondence to} Dr Fiona Finlay, Child Health Department, Sirona Care and Health, Newbridge Hill, Bath BA1 3QE, UK;

Fiona.finlay@sirona-cic.orh.uk

Received 12 September 2012 Revised 13 May 2013 Accepted 25 May 2013 Published Online First 3 July 2013

\begin{tabular}{l}
\hline To cite: Jones R, Finlay F. \\
Postgrad Med J \\
2014;90:69-74. \\
\hline
\end{tabular}

\title{
Medical students' experiences and perception of support following the death of a patient in the UK, and while overseas during their elective period
}

\author{
Rachel Jones, ${ }^{1}$ Fiona Finlay ${ }^{2}$
}

\begin{abstract}
Aims To investigate medical students' experiences and perception of support following a patient's death, contrasting their experiences in the UK, and while overseas during their elective period.

Methods An anonymous online questionnaire was distributed to all final year medical students at one UK medical school in November 2009.
\end{abstract}

Results 220 students were contacted, 60\% responded. $72 \%$ (94) of medical students had been involved in endof-life care at some point during their course; students on elective experiencing patient death across all ages. Some students saw many patients dying during their elective period. Students had mixed emotions following a patient's death. In the UK, students reported feeling shocked, upset and sad. When overseas, many students were angry or frustrated, and many reported feelings of injustice. Following a death, students found talking to people beneficial, but when overseas they turned to friends and family using email and Facebook, rather than talking to local doctors and nurses. Only $13 \%$ (16) of medical students thought their medical training had prepared them sufficiently to deal with death. Of those who did feel prepared some said they had gained this knowledge through working as a healthcare assistant. Conclusions Students feel ill prepared for experiencing the death of a patient. Even though they may have 'medical knowledge' they are still lacking in emotional support and are often inadequately supported around the time of a patient's death. Medical schools should consider their curricula so that students are aware of the possible experiences and emotions which they may face when involved with the death of a patient, and students should be given advice on whom to turn to for support.

\section{INTRODUCTION}

Medical school training should lay the foundations for a career in medicine and provide junior doctors with appropriate knowledge and skills for the first stage of their career. ${ }^{1}$ Within the UK, there is considerable variation between medical schools in how well they achieve this goal. ${ }^{1}{ }^{3}$ The results of a recent study looking at the experience of transition from medical student to junior doctor at the Peninsula Foundation School in the UK found that most found the transition stressful. ${ }^{4}$ Dealing with their newly gained responsibility, managing uncertainty, experiencing the sudden death of patients and feeling unsupported were important themes. When a death occurred, or when a patient was dying, support was often lacking, and some felt that their experience at medical school had not sufficiently prepared them for these situations.
To learn about death, students need both theoretical knowledge and personal experience. ${ }^{5}$ A study from the University of Pittsburgh showed that students with personal or professional experience of death had more positive attitudes about end-of-life care, and the authors suggested that 'medical schools should focus on developing emotionally supportive settings in which to teach students about death and dying. ${ }^{6}$ Such recommendations are not new-Hull in 1991 found that medical students had little experience of death, and often the experience they did have was acquired prior to entry to medical school. ${ }^{7}$ Their experience of death during training was often traumatic, with little opportunity for counselling, and Hull advised that 'there is a need for increased teaching about death and dying particularly before clinical training'.

Recently, a greater emphasis has been placed on teaching students about palliative care, with Tomorrow's Doctors identifying this as part of the core content for undergraduates. ${ }^{8}$ However, while some medical schools may be focusing on palliative care, acute death and dying scenarios may be overlooked. ${ }^{4}$ This aspect of the curriculum should not be neglected, as students may encounter acute deaths, sometimes in large numbers, while on their elective placement.

Electives are a highlight of many medical students' undergraduate training, providing the opportunity to travel overseas experiencing a different culture and health system. ${ }^{9} 10$ The British Medical Association (BMA) has produced two documents focusing on elective periods 'Electives for medical students' ${ }^{10}$ and 'Ethics and medical electives in resource-poor countries'. ${ }^{11}$ The BMA stresses that medical students are not professionally qualified, and working abroad does not alter this. They state 'it is both illegal and unethical for unregistered students to work as if they were qualified doctors' and that students should 'resist pressure to diagnose, prescribe or administer treatment without close clinical supervision', but they do acknowledge 'where a patient is at immediate risk of death or serious harm, and no other qualified health professional is available, students can assist, provided they have a reasonable belief that they have appropriate skills and can improve outcomes'. ${ }^{10}{ }^{11}$ Although the BMA has provided useful information for students going on their elective it focuses on personal health, travel insurance, vaccinations and HIV, and no information or advice is given about coping with the scale of morbidity, or mortality at a young age, which may be encountered in some countries, and which some students find quite shocking 
(personal communication). Students' emotional health and wellbeing is not mentioned, and no sources of support while on elective are given.

Although some studies have looked at medical students' experiences related to end-of-life issues ${ }^{12}{ }^{14}$ students' experience of death while overseas on elective periods has not previously been reported in the literature. Therefore, the aim of this study was to investigate medical students' experiences and perception of support following a patient's death, contrasting the experiences in the UK and while overseas during their elective period.

\section{METHOD}

A questionnaire was designed and piloted and then an email link was sent to all fifth year (final year) students in one UK medical school inviting them to take part in the selfadministered, anonymous questionnaire-based study. The survey took place in November 2009 immediately after students returned from their elective placement. The questionnaire was made available online at http://www.surveymonkey.com.

\section{THE QUESTIONNAIRE}

The questionnaire comprised 30 questions requiring tick-box answers, with space left for free text comments (see online supplementary appendix 1). It included six sections:

1. Age of the medical student and elective destination

2. Information on patient(s) who died on elective period

3. Students feelings and support after a death on elective

4. Information on patient(s) who died in UK

5. Students feelings and support after a death in UK

6. Suggestions for improvement in teaching and preparation for elective

The questions were designed to meet the aims of the study asking students about their experience while in the UK and while on their elective period. Students views were obtained on their initial feelings following a patient's death, time for reflection, support networks and debriefs. They were also asked whether the course had prepared them sufficiently to deal with a patient's death and what further information would have been useful prior to their elective period. Students were informed that they could contact their personal tutor or the faculty student advice service if reading the questionnaire reopened any unresolved issues, or if they required further support or advice, and the appropriate contact details were provided. A reminder email was sent to students 1 week after sending out the initial questionnaire.

\section{DATA ANALYSIS}

The results were analysed both quantitatively and qualitatively. Filters built into the online questionnaire programme enabled responses to be explored quantitatively comparing experiences while in the UK and while overseas. The qualitative free text comments were analysed manually by both authors using thematic analysis. Independently, the authors highlighted any emerging themes, and their results were combined to look for overlapping themes, enabling the authors to contrast students' experience in the UK and while on their elective period.

Students were asked for their suggestions on improvement, and these responses were drawn together as proposals to provide better support for students when they experience the death of a patient, both in the UK and while on their elective period.

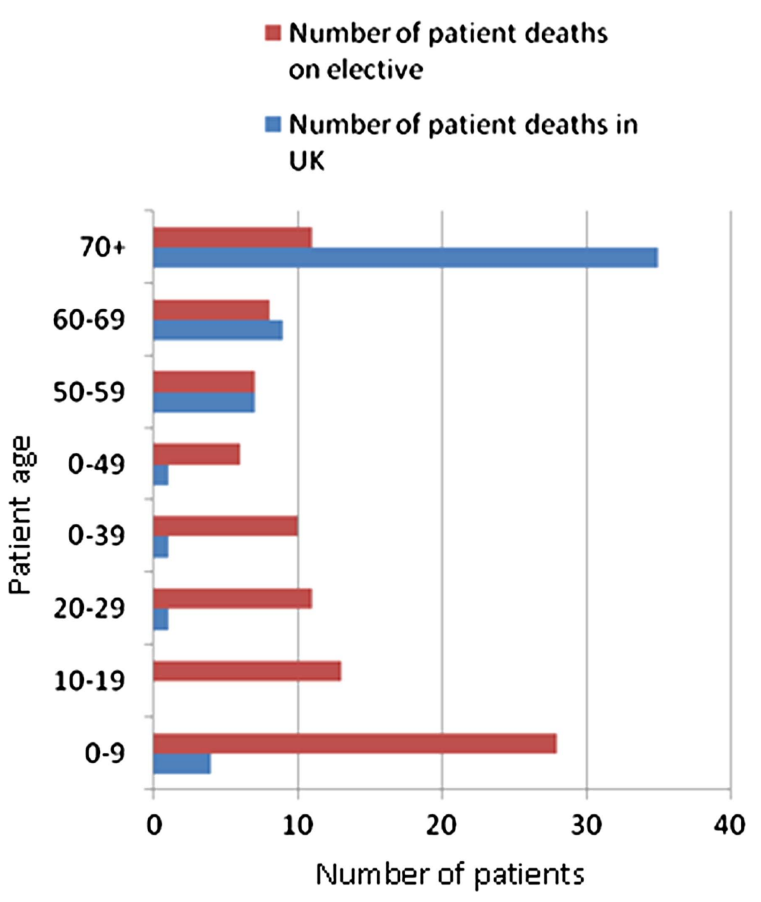

Figure 1 Bar chart comparing number and age distribution of patient deaths in UK and on elective. Access the article online to view this figure in colour.

\section{RESULTS}

Only 131 of 220 questionnaires were returned, a response rate of $60 \%$. Eight questionnaires were partially completed, and their responses were included if the relevant question was answered.

The ratio of male:female respondents was $29: 71$, a reflection of the medical school sex ratio with more female students (34: 66 split $-p$ value 0.23 ). There was a global mix of elective destinations.

Overall, 72\% (94/131) medical students had been involved with end-of-life care at some point during their training; 49\% $(60 / 123)$ students saw patients die while on clinical placement in the UK, and $45 \%(56 / 125)$ on elective. On electives, students experienced patient death across all age ranges in comparison with deaths experienced in the UK, where most of the patients who died (35/60-58\%) were over 70 years of age (see figure 1 ). Some students saw many patients dying during their elective period.

More students were involved in resuscitation while on elective compared with when they were in the UK (22 students $(41 \%)$ compared with 14 students $(23 \%)(\mathrm{p}<0.05)$. No students were involved in resuscitation by themselves while in the UK, whereas, 14 resuscitated patients by themselves (26\%) while abroad with no qualified doctors available to assist $(\mathrm{p}<0.05)$ (see table 1).

Table 1 Students involved in resuscitation while on elective and while in UK

\begin{tabular}{lll}
\hline & Elective \% (number) & UK \% (number) \\
\hline Involved in end-of-life care & $45(56 / 125)$ & $49(60 / 123)$ \\
Witnessed resuscitation & $65(35 / 54)$ & $42(25 / 60)$ \\
Involved in resuscitation & $41(22 / 54)$ & $23(14 / 60)$ \\
Resuscitation alone & $26(14 / 54)$ & 0 \\
\hline
\end{tabular}


Themes emerging from the qualitative responses, and illustrated with quotations below, included 'dealing with emotions', 'global support networks' and 'best teaching methods'.

\section{Students initial feelings}

Students generally reported feeling very upset when a patient died, but experienced more raw emotions on elective overseas, some witnessing many deaths (figure 2).

While in the UK, students reported 'sadness and numbness', 'shocked and upset', 'emptiness, fragile'. Some expressed feelings of relief, 'relief-they were in a lot of pain'. 49\% (60/123) of students had been involved in end-of-life care in the UK, with $42 \%$ witnessing resuscitation. One student reported in a strange way I felt excited and pleased that I had partaken in what I thought to be a very important part of practical medical training'.

While overseas, one student summarised their experience as 'shock, horror, tears, panic', and some said they were 'openly crying'. Some witnessed many deaths-'I never thought I'd say this but I lost count'. Many students were angry or frustrated when a patient died-'angry at myself, worried that I didn't do enough' and they also reported feelings of injustice-'she wouldn't have died had she been in the UK'. Some commented on a lack of resources 'there was nothing available to resuscitate with-no fluids, oxygen or drugs'. Fourteen students resuscitated patients on their own sometimes because they were the most qualified person present-'there were no doctors at the hospital'. Some were shocked by what they witnessed-'death was pretty horrible-patient died from septic shock from burns all over their body'. Twenty-eight students saw children aged 09 years dying (three students witnessing multiple deaths)—'I had previously seen the child relatively well, shock-never seen anyone die before', 'so young ....'.

\section{Time for reflection}

In the UK, although doctors and nurses played a key role in discussing the patient's death with the students, only 40\% (24/59) felt they had long enough for reflection before going back to work.

$\begin{array}{ll}\text { Number of deaths on } & \text { Number of deaths on } \\ \text { elective in a developing } & \text { elective in a developed } \\ \text { country } & \text { country }\end{array}$

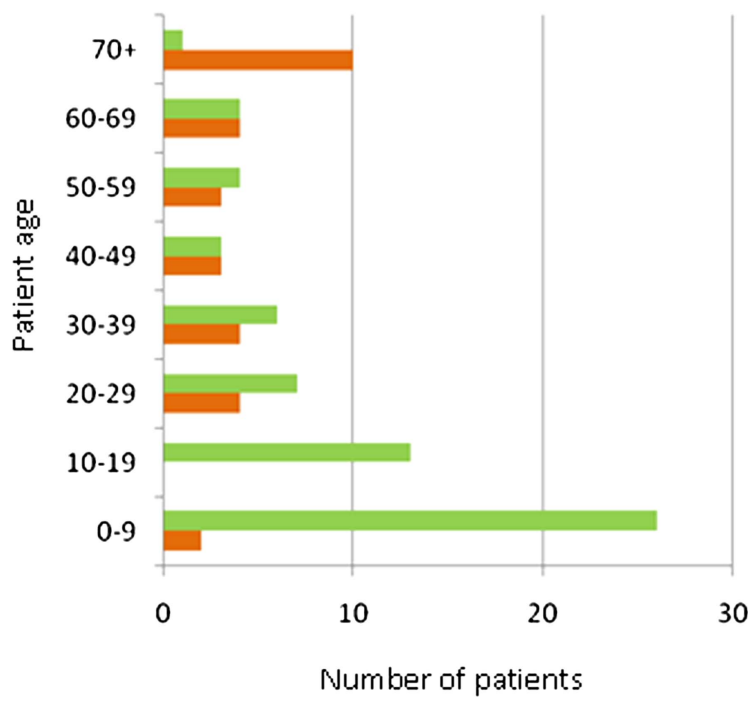

Figure 2 Bar chart comparing number and age distribution of patient deaths on elective in developed versus developing countries. Access the article online to view this figure in colour.
On elective, only $16 \%$ (9/55) of students felt they had time to reflect on a patient's death. The majority reported having no time to reflect-'I was encouraged to see more patients despite being in tears', 'we had to continue as there would be a queue of children needing to be seen'.

\section{Support network}

On both UK and elective placements, the majority (76\% (41/54) and $78 \%$ (40/51), respectively) found talking to someone beneficial. On elective, students looked globally for support turning to friends and family first, rather than receiving support locally - 'didn't want to burden people'. They used social network sites and email-'I sent a long email to my parents, was really upset, good to vent'. Although students had a more formal support network in the UK only 26\% (13/51) talked with doctors and 8\% (4/51) with nurses, while 50\% (25/51) talked to family and friends.

Some students mentioned that they would have liked more general support, for example, several students were caught in the tsunami in the Asia-Pacific region, and some received 'no response' when trying to reach their medical school. They suggested having an emergency contact number to reach a faculty member at any time.

\section{Debriefs}

On elective, only $14 \%(8 / 56)$ of students were involved in a debrief following a death compared with 37\% (21/58) students in the UK. While on their elective, students wanted to learn from their experiences: 'I would have liked to talk to someone and learn from this and see if there was anything else I could have done'. Although only $37 \%$ had a debrief in the UK, many appreciated this experience 'we had a debrief afterwards which was very helpful', 'consultants debriefed us afterwards, gave us the day off to go and relax and think about it. Much more positive than the experience overseas'.

\section{Medical education}

The students taking part in the study attended a medical school with a traditional integrated curriculum. Students are based at the university in years 1 and 2, and in years 3-5 teaching is delivered in hospitals around the region. Students go on their elective between their 4 th and 5 th years. This questionnaire was conducted following their elective period and prior to their 1-month palliative care block. Only 13\% (16/125) of medical students thought their course had prepared them sufficiently to deal with patient death-'I don't think I've had any formal teaching on death'. Others questioned the best way to learn 'not something that you can prepare someone for with lectures and role play'. Of those who did feel prepared many said had gained this knowledge in other ways, for example, through working as a healthcare assistant. Some students had not yet seen a patient die and some were not sure how they would cope - I feel totally unprepared to see a patient die and am trying to avoid it', 'I think if I was left alone I'd fall apart'.

Prior to their elective period, students commented that they would benefit from a lecture on 'dealing with death' and a lecture on 'medicine in resource poor settings'.

\section{DISCUSSION}

Medical students' experiences and perception of support following the death of a patient were different depending on whether they were on their elective abroad or in the UK. Students were more likely to see young children dying while abroad and many felt inadequately prepared. More students were involved in 
resuscitating patients while abroad, and some were left with feelings of injustice and inadequacy. Rather than seeking support from the local health team they often sought support globally from friends using social network sites and email.

Medical students are rarely at the bedside when a patient dies, ${ }^{15}$ and many students in this study felt unprepared to be involved with a patient's death. Although teaching about death and end-of-life care can be 'problematic for educators and the profession', ${ }^{16}$ students welcome the opportunity to learn about death and dying, ${ }^{17}$ and it is important that the theme of 'death and dying' is integrated into teaching early in the curriculum. There are many opportunities for discussions about death during lectures, on clinical attachments, on acute and long-stay wards, and during palliative care placements ${ }^{18}{ }^{20}$; however, the teaching provided by medical schools is very variable, ${ }^{21}$ and having an 'individual lead or champion' and 'university support' are important when trying to influence the curriculum. ${ }^{22}$ Some universities have used innovative educational programmes to teach students about death. Rucker ${ }^{23}$ has used a creative humanitiesbased assignment with third year students to help them reflect on the process of becoming a doctor, exploring issues such as coming to terms with death and dying, and coping with professional stress, and MacLeod has used a personal reflection portfolio approach. ${ }^{16}$ McIlwaine has piloted an interprofessional teaching session with medical students and social work students, exploring the students' own feelings and the practical aspects of death (confirmation, death certification and last offices), coupled with discussion about the grief process. ${ }^{24}$

Exposure to death as a student may influence attitudes and knowledge as a qualified doctor. A study from the University of California found that all third year medical students encountered death or dying patients during their first internal medicine clerkship, and their relationships with patients were characterised by attachment, empathy and advocacy. ${ }^{25}$ The experience affected students' emerging professional identities, giving them the opportunities to manage strong emotions. There is little written in the medical literature about managing emotions, ${ }^{26}$ and although several students in this study reporting 'openly crying', it is a topic which is rarely discussed. ${ }^{27}$ Wagner found that $57 \%$ of doctors, $76 \%$ of nurses and $31 \%$ of medical students had cried at work at least once, generally when identifying suffering or crying with dying patients or their families. Medical students reported the highest percentage of negative social consequences of their crying, sometimes being ridiculed or screamed at. ${ }^{28}$ It is important to remember that 'staff grief is real', 29 'doctors are moved by the deaths of the strangers for whom they care and are often powerfully affected by the death'. ${ }^{31}$ Grief may affect staff at all stages of their career-Behnke ${ }^{32}$ found that paediatric house officer grief reactions were similar to grief responses experienced with the death of a loved one, and a study of paediatric consultants found that 'although many have built up personal support networks and individual coping strategies many recognise that these are not all encompassing and some harbour unresolved feelings of grief'. ${ }^{3}$ Redinbaugh found that female doctors experienced stronger emotional responses when a patient died. ${ }^{34}$

Although a Cochrane review ${ }^{35}$ has suggested that debriefs may increase the incidence of post-traumatic stress disorder, some students in this study found debriefs helpful. Bereavement counsellors, individual debriefs and team meetings are all forms of positive support which could be introduced into the medical school curricula to help students cope with death. ${ }^{36}$ It is essential that students learn to 'look after themselves' taking time for reflection, relaxation and non-clinical activities, as this may minimise the risk of future depression, burnout and poor judgement. ${ }^{37}$
International electives have educational benefits and contribute to well-rounded training for medical students, ${ }^{38}$ however, students should have more information about what to expect in different countries with formal sessions addressing the psychological, as well as the practical aspects of an elective overseas prior to departure. Some medical schools deliver global health teaching prior to students going on elective, ${ }^{39}$ and this may address some of the concerns raised by respondents in this study. Students must be properly supported while abroad, and they should have a $24 \mathrm{~h}$ emergency contact number for their medical school which they can use if they get into difficulties while abroad. Students should not have to rely totally on friends and family for support, as was the case with some respondents in this study who received a lot of support via social networking sites. Elit ${ }^{40}$ conducted semistructured interviews on students returning from their elective period and concluded that as well as having formal predeparture training they should have an on-site supervisor while abroad, they should be able to maintain an ongoing connection with their university, and have a formal debriefing session on their return. The General Medical Council gives clear guidance-'Students must have appropriate support for their academic and general welfare needs at all stages. Medical schools must produce information about the support networks available, including named contacts for students with problems. Students taking student-selected components (SSCs) that are taught in other departments or by other medical schools, and those on clinical attachments or on electives, must have access to appropriate support'.

\section{LIMITATIONS}

Our study is limited by the fact that it was performed at a single medical school, and sociodemographic details, such as ethnicity, graduate status or religious affiliations of respondents were not recorded. Further research is required to see if these factors effect medical students' emotional reactions following the death of a patient. We do not know whether the $60 \%$ of respondents were different from the $40 \%$ of non-respondents. Some nonrespondents may have had no experience of death, and therefore felt that their opinion would add little to the study. Other nonrespondents may have witnessed traumatic deaths and decided not to complete the questionnaire as they did not want to 'relive the experience'. However, others with negative experiences may have been keen to share their views with us, hoping the situation may improve for students in the future. Despite these limitations we do believe that the study gives us some insight into medical students' experiences and perception of support following a patient's death while on elective placements and in the UK. Some students feel there are clear deficiencies in their teaching, training and support structures, and we must strive to improve this. Further work is required to evaluate different teaching modules on 'death and dying' to identify best educational practice.

\section{CONCLUSION}

This paper explores medical students' experiences and perception of support following the death of a patient. Their experiences and feelings were different depending on whether they were abroad on elective or on placement within the UK. Students were more likely to be involved in resuscitation and see young children dying while abroad, and many felt inadequately prepared and unsupported, frequently feeling angry or frustrated. They often turned to friends globally for support rather than seeking support from the local health team.

Medical student teaching is often dependent on clinical placements, and may vary significantly from student to student. Medical schools need to introduce the theme of 'death and 
dying' at an early stage of the curriculum, and should make students aware of the possible experiences and emotions following the death of a patient and give them advice on whom to turn to for support while at home and abroad.

\section{Main messages}

- Many medical students feel unprepared to deal with the death of a patient.

- Elective placements may expose students to a large number of patient deaths, especially children.

- Students on elective placements experienced rawer emotional reactions to death and had less support than when in the UK.

\section{Proposals to improve medical students' experience} in the future

- Integrate the theme of 'death and dying' at an early stage of the curriculum.

- Ensure that medical students are involved in team debrief sessions following the death of a patient.

- Arrange formal sessions to address the psychological as well as the practical aspects of an elective overseas.

- Ensure that students have a $24 \mathrm{~h}$ emergency contact number for a member of the medical school faculty while abroad.

\section{Current research questions}

- To investigate the effect of age, sex, ethnicity and socioeconomic class on the emotional reactions following the death of a patient among medical students and doctors.

- To evaluate a variety of teaching modules on 'death and dying' to identify best educational practice.

- To develop and evaluate an 'elective tool kit'.

\section{Key messages}

- Brennan N, Corrigan 0, Allard J, et al. The transition from medical student to junior doctor: today's experiences of Tomorrow's Doctors. Med Educ 2010;44:449-58.

- General Medical Council. Tomorrow's doctors. GMC: London, 2009 (updated Oct 2011). http://www.gmc-uk.org/ Tomorrow_s_Doctors_1011.pdf_48905759.pdf.

- British Medical Association. Electives for medical students. London: BMA, 2009.

- British Medical Association. Card thirteen: medical electives in resource poor countries. London: BMA, 2009. http://bma. org.uk/practical-support-at-work/ethics/medical-studentsethics-tool-kit/medical-electives-in-poor-countries.

- Buss MK, Marx ES, Sulmasy DP. The preparedness of students to discuss end-of-life issues with patients. Acad Med 1998;73:418-22.
Acknowledgements We would like to thank those who took the time to complete the questionnaire.

Contributors Both authors were involved in questionnaire design, literature review and writing the paper. RJ submitted the work to the ethics committee.

Competing interests None.

Ethics approval The study was approved by the Faculty of Medicine and Dentistry Committee for Ethics.

Provenance and peer review Not commissioned; externally peer reviewed.

\section{REFERENCES}

1 Goldacre MJ, Taylor K, Lambert T. Views of junior doctors about whether their medical school prepared them well for work: questionnaire surveys. BMC Med Ed 2010;10:78.

2 Goldacre MJ, Lambert T, Evans J, et al. Pre-registration house officers' views on whether their experience at medical school prepared them well for their jobs: national questionnaire survey. BMJ 2003;206:1011-12.

3 Cave J, Woolf $\mathrm{K}$, Jones $\mathrm{A}$, et al. Easing the transition from student to doctor: how can medical schools help prepare their graduates for starting work? Med Teach 2009:31:403-8

4 Brennan N, Corrigan 0, Allard J, et al. The transition from medical student to junior doctor: today's experiences of Tomorrow's Doctors. Med Educ 2010;44:449-58.

5 Wear D. "Face-to-face with It": medical students' narriatives about their end-of-life education. Acad Med 2002:77:271-7.

6 Anderson WG, Williams JE, Bost JE, et al. Exposure to death is associated with positive attitudes and higher knowledge about end-of-life care in graduating medical students. J Palliat Med 2008;11:1227-33.

7 Hull FM. Death, dying and the medical student. Med Educ 1991;25:491-6.

8 General Medical Council. Tomorrow's doctors. GMC: London, 2009 (updated Oct 2011). http://www.gmc-uk.org/Tomorrow_s_Doctors_1011.pdf_48905759.pdf.

9 Nishigori $\mathrm{H}$, Otani T, Plint S, et al. I came, I saw, I reflected: a qualitative study into learning outcomes of international electives for Japanese and British medical students. Med Teach 2009;31:196-201.

10 British Medical Association. Electives for medical students. London: BMA, 2009

11 British Medical Association. Card thirteen: medical electives in resource poor countries. London: BMA, 2009. http://bma.org.uk/practical-support-at-work/ethics/ medical-students-ethics-tool-kit/medical-electives-in-poor-countries.

12 Buss MK, Marx ES, Sulmasy DP. The preparedness of students to discuss end-of-life issues with patients. Acad Med 1998;73:418-22.

13 Fraser HC, Kutner JS, Pfeifer MP. Senior medical students' perceptions of the adequacy of education on end-of-life issues. J Palliat Med 2001;4:337-43.

14 Ahmedzai S. Dying in hospital: the residents' viewpoint. BMJ 1982:285:712-14.

15 Bascom P, Vetto JT, Osborne M. Clinical experiences of medical students in Oregon with dying patients. J Cancer Ed 1999:14:137-9.

16 MacLeod RD, Parkin C, Pullon S, et al. Early clinical exposure to people who are dying: learning to care at the end of life. Med Educ 2003;37:51-8.

17 Rappaport W, Witzke D. Education about death and dying during the clinical years of medical school. Surgery 1993;113:163-5.

18 Kaye JM, Loscalzo G. Learning to care for dying patients: a controlled longitudinal study of a death education course. J Cancer Ed 1998;13:52-7.

19 Dickinson GE. A quarter century of end-of-life issues in US medical schools. Death stud 2002;26:635-46

20 Billings JA, Block S. Palliative care in undergraduate medical education. Status report and future directions. JAMA 1997;278:761-3.

21 Gibbins J, McCoubrie R, Maher J, et al. Recognising that it is part and parcel of what they do: teaching palliative care to medical students in the UK. Palliative Med 2010:24:299-305

22 Gibbins J, McCoubrie R, Maher J, et al. Incorporating palliative care into the undergraduate curricula: lessons for curriculum development. Med Educ 2009:43:776-83.

23 Rucker L, Shapiro J. Becoming a physician: students' creative projects in a third-year IM clerkship. Acad Med 2003:78:391-7.

24 Mcllwaine L, Scarlett V, Venters A, et al. The different levels of learning about dying and death: an evaluation of a personal, professional and interprofessional learning journey. Med Teach 2007;29:e151-9.

25 Ratanawongsa N, Teherani A, Hauer KE. Third-year medical students' experiences with dying patients during the internal medicine clerkship: a qualitative study of the informal curriculum. Acad Med 2005;80:641-7.

26 Williams CM, Wilson CC, Olsen CH. Dying, death, and medical education: student voices. J Palliat Med 2005;8:372-81.

27 Mehta R. Is it OK for physicians to cry? Institute to enhance palliative care: Palliative care case of the month 2010;10. http://www.dom.pitt.edu/dgim/SPC/ cases/October2010.pdf

28 Wagner RE, Hexe IM, Bauer WW, et al. Crying in hospitals: a survey of doctors', nurses and medical students' experience and attitudes. Med J Aust 1997:166:13-16. 
29 Nesbit MJ, Hill M, Peterson N. A comprehensive Pediatric bereavement Program: The patterns of your life. Crit Care Nurs Q 1997;20:48-62.

30 Baverstock A, Finlay F. Specialist registrars' emotional responses to a patient death. Arch Dis Child 2006;91:774-6.

31 Jackson VA, Sullivan AM, Gadmer NM, et al. "It was haunting ..." physicians" descriptions of emotionally powerful deaths. Acad Med 2005;80:648-56.

32 Behnke $M$, Reiss J, Neiimeyer $G$, et al. Grief responses of pediatric house officers to a patient's death. Death Stud 1987;11:169-76.

33 Baverstock $A$, Finlay $F$. What can we learn from the experiences of consultants around the time of a child's death? Child Care Health Dev 2008;34:732-9.

34 Redinbaugh EM, et al. Doctors' emotional reactions to recent death of a patient: cross sectional study of hospital doctors. BMJ 2003;327:185.
35 Rose S, Bisson J, Churchill R, et al. Psychological debriefing for preventing post traumatic stress disorder. Cochrane Database Syst Rev 2002(2):CD000560.

36 Baverstock A, Finlay F. A Study of Staff Support Mechanisms within Children's Hospices. Int J Palliat Nurs 2006;12:506-8.

37 Pfifferling JH, Blum JC, Wood W. The prevention of physician impairment. J Fla Med Assoc 1981;68:268-73.

38 Jeffrey J, Dumont RA, Kim GY, et al. Effects of international health electives on medical student learning and career choice: results of a systematic literature review. Fam Med 2011;43:21-8.

39 Dotchin C, van den Ende C, Walker R. Delivering global health teaching: the development of a global health option. Clin Teach 2010;7:271-5.

40 Elit L, Hunt M, Redwood-Campbell L. Ethical issues encountered by medical students during international health electives. Med Educ 2011;45:704-11. 